\title{
Redesign of Drive Shaft's tripod Assembly, to improve the performance \& reduce failure
}

\author{
R. Harikrishnan*, S. Anantharaman ${ }^{*}$, G. C. Sreenath ${ }^{* *}$, B. Deenadayalan ${ }^{* *}$ \\ "Dep't of Mechanical Engineering, College of Engineering,Anna University, Guindy, Chennai, India \\ ${ }^{* *}$ GKN Driveline India Ltd, Oragadam, India
}

\begin{abstract}
The aim of the project is to enhance the performance of the drive shaft's tripod assembly to reduce failure and to increase the performance of the product. Drive shaft transfer the engine power to the wheels and it allows for steering and suspension movement and reduce vibration for the driver. Loss of drive in the vehicle due to inboard / Tripod assembly damage (Drive shaft inboard joint failure). Reducing the Failure of drive shaft improves performance and warranty life for both existing product and new product. Even though the interconnecting shaft was intentionally made for fail during excessive loading, unfortunately the inboard joint fractures during static testing and on field. The failure due to the inboard joint (Tripod assembly roller damage) is high. Objective is to find the Root cause for tripod assembly Failure, by the Adams simulation case study, It has been observed bottom needle only getting loaded with the maximum load of $27 K N$ and to improve the static load test load has to be uniformly distributed or roller and Needle geometry has to be improved to withstand the load. The aim of the project is to design and develop a tripod assembly withstand Minimum $1600 \mathrm{Nm}$. design.
\end{abstract}

Keywords: Adams,Drive shaft tripod Assembly.t

\section{INTRODUCTION}

A constant velocity joint is a mechanical coupling in which the rotational speed of the output shaft is the same as that of the input shaft whatever the operating angle of the joint. In most applications, the inboard CV Joint is a plunge joint that allows the effective length of the side shaft to change due to suspension travel. In front (or steer) axle applications, the outboard joint must transfer torque effectively through a wide angle (up to 52 degrees). In rear axle applications, joint operating angles are much lower. Constant-velocity joints (CV joints) allow a drive shaft to transmit power through a variable angle, at constant rotational speed, without an appreciable increase in friction or play. They are mainly used in front wheel drive and many modern Rear wheel drive cars with independent rear suspension typically use $\mathrm{CV}$ joints at the ends of the rear axle half shafts, and increasingly use them on the prop shafts.

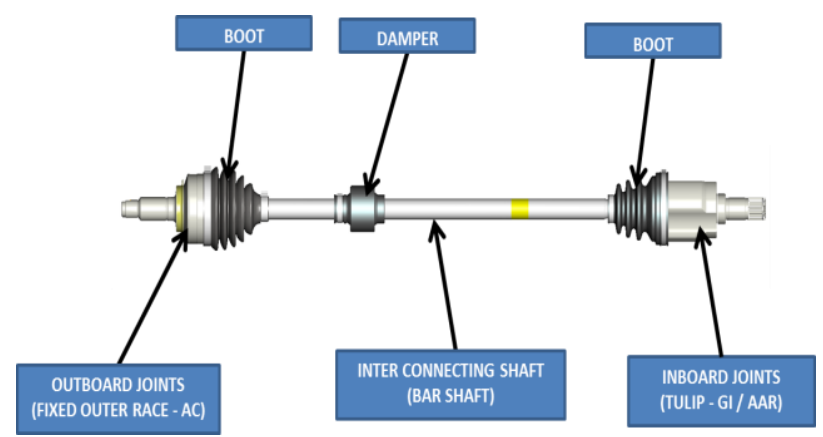

Figure 1 -Drive shaft Assembly.

Drive shaft Assemblyredesign project is been carried out to improve the performance \& reduce failure of existing Drive shaft valve, the main goal is to improve the performance without increasing the product cost. In this paper we are discussing how tripod Assembly is redesigned.

\section{TRIPOD ASSEMBLY}

A tripod where the axe of its trunions, contained in clean perpendicular to interconnecting shaft.Makes an angle of 120 degree with the other two trunions.A tulip or inboard joint includes three cylindrical track parallel to the tulip`s axis and equally spaced, angularly and radially around this axis.Three spherical rollers externally assuring the link between the tripod and the tulips, in such a way that each of the tripod trunions axes cuts each of the three tracks axes following the assembly.. The current design of Tripod Assembly, showing its parts used in Drive Shaft assembly is shown in the Fig.2. 


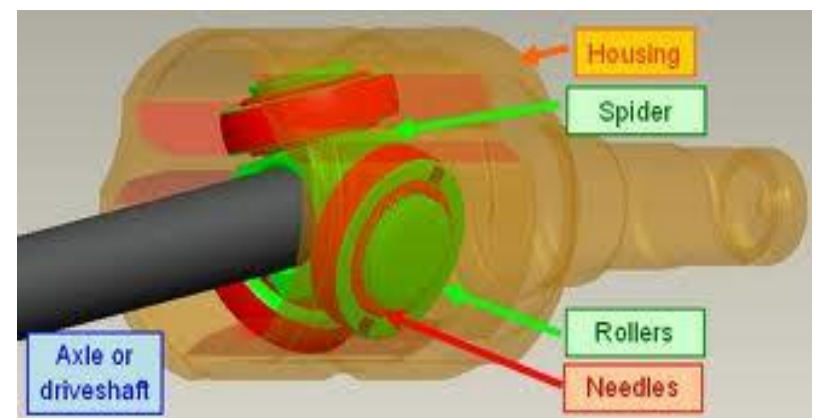

Figure 2-Existing tripod Assembly.

The existing tripod assembly has three spherical PEG and 32 rollers assembled with one roller in each Tripod PEG, which comprises a retaining ring made of spring steel to hold the protection roller in tripod body, a Roller will rotate in tulip track diameter when the torque transmitted from engine then the tripod assembly rollers will be subjected to load.During the study of various Tripod assemblies it is observed that elliptical profile tripod body is having better contact angle.(Ovality - $0.1 \mathrm{~mm}$ )). So it is decided to adapt the oval shape perpendicular to the spline axis. A tripod assembly for existing design as shown in Fig.3.

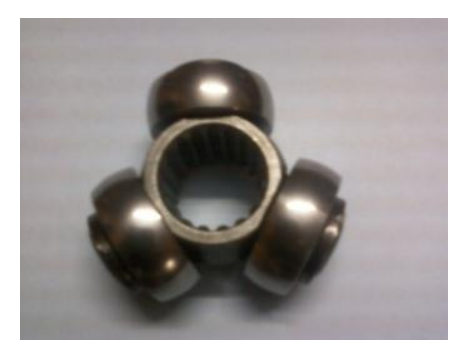

Figure 3-Tripod assembly.

Requirements of Drive shaft - Tripod assembly is provided in Table 1, the capability of tripod assembly to with stand the static load up to $1500 \mathrm{Nm}$ in Drive shaft assembly. The main task is to check the capability of Tripod assembly for static load.

\begin{tabular}{|c|c|}
\hline Parameter & Requirement \\
\hline Outboard Joint Articulation Angle: $25^{\circ}$ & $25^{\circ}$ \\
\hline Inboard Joint Articulation Angle: $10^{\circ}$ & $10^{\circ}$ \\
\hline Joint Position from design center line: $0.0 \mathrm{~mm}$ & $0.0 \mathrm{~mm}$ \\
\hline Rotational Speed - From: $2.0 \mathrm{rpm}$ & $2.0 \mathrm{rpm}$ \\
\hline Rotational Speed - To: $50.0 \mathrm{rpm}$ & $50.0 \mathrm{rpm}$ \\
\hline Load Applying Units: Nm/rev & $\mathrm{Nm} / \mathrm{rev}$ \\
\hline Load Applying Rate: 20.0 & 20 \\
\hline Static load (No fracture) & Min $>=1500 \mathrm{Nm}$ \\
\hline
\end{tabular}

Table 1-Requirement for Tripod Assembly

III. EXPERIMENTATION

Experimentation is carried out with existing static torsion load cover for measuring the withstanding capability of standard performance by increasing the ovality from $0.02 \mathrm{bar}$ to $0.1 \mathrm{~mm}$ gradually. Experimental setup is shown in Fig.4.

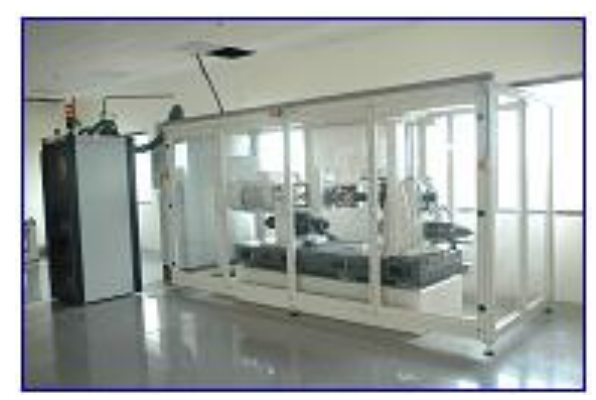




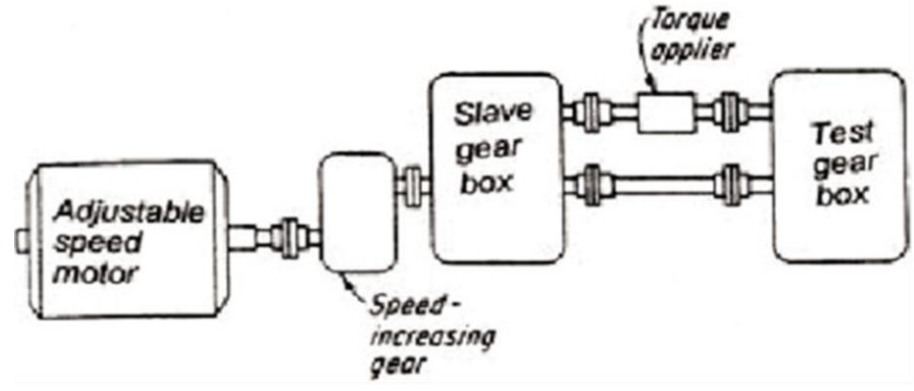

Figure 3-Experimental setup for static torsion test rig.

The tripod assembly with standing strength can be improved by two ways, one is improving structurally by making trunion shape and by increasing the roller diameterso that it will not get fracture and another way is to reducing the failure acting on tripod assembly by optimizing the trunion shape so that even for high static load with tripod up to $1700 \mathrm{Nm}$ the facture will not happen, this paper describes how static load acting on tripod assembly failure is reduced by using ADAMS as tool.

\section{ADAMS MODEL DESCRIPTION}

The loads that contribute to the rollers in the existing tripod assembly are

- $\quad$ The Static \& Dynamic load produced by the tripod trunion

- $\quad$ The Static \& dynamic friction load produced by the needls

- The static and dynamic load applied on the ID of Rollers

The loads contribution to Rollers in existing tripod assembly is shown in fig 5.2.

This section illustrates the procedure followed for building a mathematical model, discretization of a computational domain, porous modeling, and ADAMS solver set up. ADAMS, a design oriented Pro-E modeling code was selected to investigate and optimize the tripod Assembly, The Load domain was created by considering the cavity inside the geometry by utilizing the CAD modeling package Pro Engineer. Complete cross section of the Tripod Assembly is shown in the Fig.5

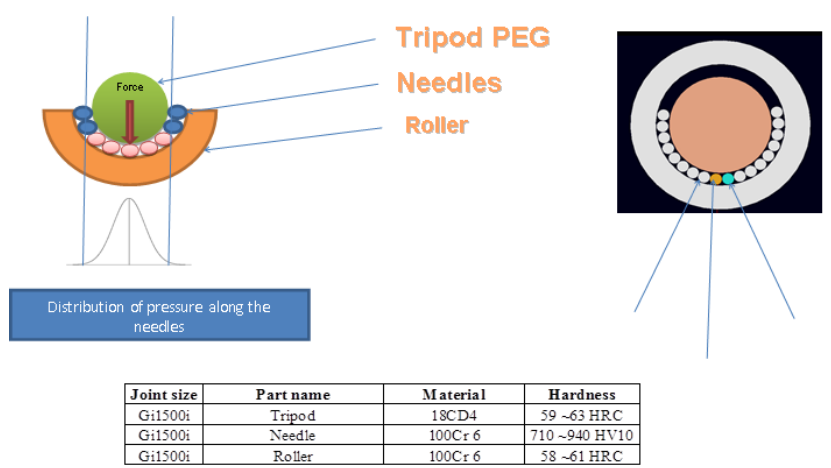

Figure 5-Tripod PEG cross section for ADAMS simulation

Force calculation:-

Torque $=$ Force $\mathrm{x}$ Radius $($ Unit $:-\mathrm{Nm})$

Force $=$ Torque $\quad($ Unit $:-\mathrm{N})$

Radius

Tripod torque Specification:

Torque requirement - Max $1600 \mathrm{Nm}$

Radius of Bar shaft - 10.95 mm or $0.01095 \mathrm{~m}$

Force $=1600 \quad=146118.7 \mathrm{~N}$ 0.01095

Hence load to be applied on Tripod PEG is 146119 per PEG

Also modeled to understand the peak load applied Needle as shown in Fig.6. 


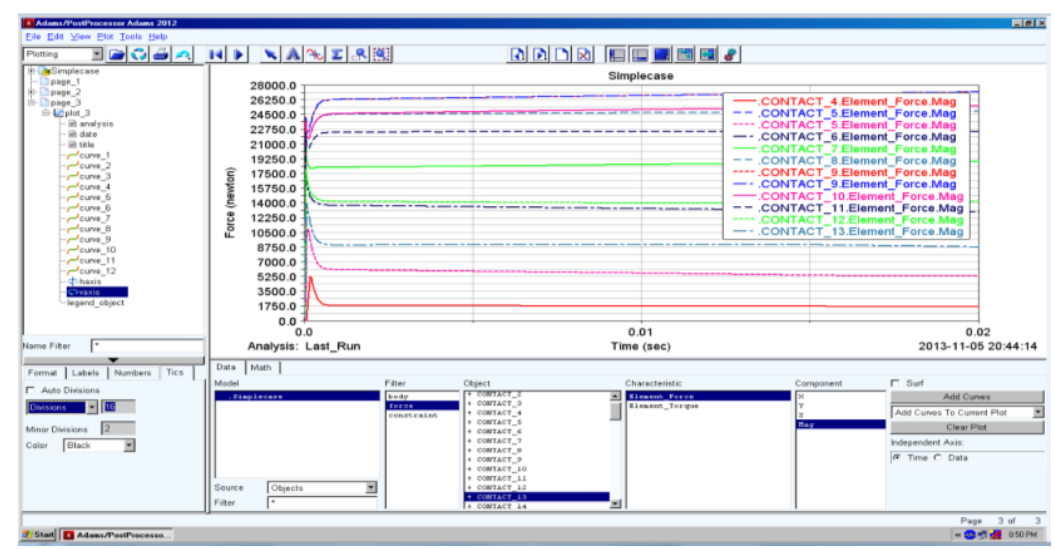

Figure 6- Tripod Assembly load distribution

\section{MAXIMUM SHEAR STRESS EQUATIONS}

Maximum Shear stress calculation:

Data:-

Roller ID = RA $=\varnothing 10.945 \times 10-3 \mathrm{M}$

Needle Diameter $=\mathrm{RB}=\varnothing 1 \times 10-3 \mathrm{M}$

Length of roller $=10 \times 10-3 \mathrm{M}$

Poison ratio $=0.3$

Young`s modulus $=2.1 \times 1011 \mathrm{~Pa}$

Load per PEG $=48706 \mathrm{~N}$

To find Maximum shear stress:-

Contact area dimension $=\mathrm{b}=\frac{4 W R^{\prime}}{\pi I E^{\prime}} 1 / 2$

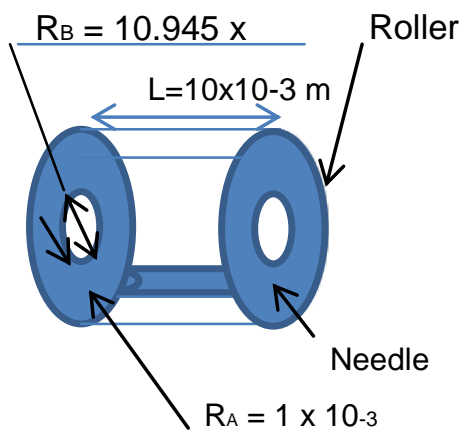

$$
\begin{aligned}
& =\frac{\mathbf{1}}{\boldsymbol{R} x}=\frac{\mathbf{1}}{\boldsymbol{R a x}}+\frac{1}{R b x}=\frac{1}{1 \times 10-3}+\frac{1}{10.945 \times 10-3}=1091.36 \\
& \frac{\mathbf{1}}{\boldsymbol{R}^{\prime}}=\frac{\mathbf{1}}{\boldsymbol{R} \boldsymbol{x}}=\frac{1}{1091.36}=9.16 \times 10-4 \mathrm{M}
\end{aligned}
$$

Contact area dimension $=b=\frac{4 \times 46706 \times 9.16 \times 10-4}{3.142 \times 10 \times 10-3 \times 2.308 \times 10+11}$

$$
=1.57 \times 10-4
$$

Maximum contact pressure $=\mathrm{P} \max$

$$
=98.82 \mathrm{Mpa}
$$

Maximum Shear stress $=\mathrm{T} \max =0.304 \times 98.82$

Yield stress of roller

$$
\begin{aligned}
& =30.04 \mathrm{Mpa} \\
& =35 \mathrm{Mpa}
\end{aligned}
$$

Maximum Shear stress calculated is < than Yeild stress of roller.

\section{STUDY OF EXISTING DESIGN}

The existing Tripod Assembly which has 32 Needles, one roller on one tripod PEG diameter. By varying the PEG diameter ovality from $0.02 \mathrm{~mm}$ to $0.12 \mathrm{~mm}$ respectively, where at $0.08 \mathrm{~mm}$ is normal operating static load is experimental for which the static load has to withstand. The Static load on Tripod assembly is studied for various ovality,relative comparison of static load is arrived. Same tripod body range is maintained to know the difference in the load distribution. 


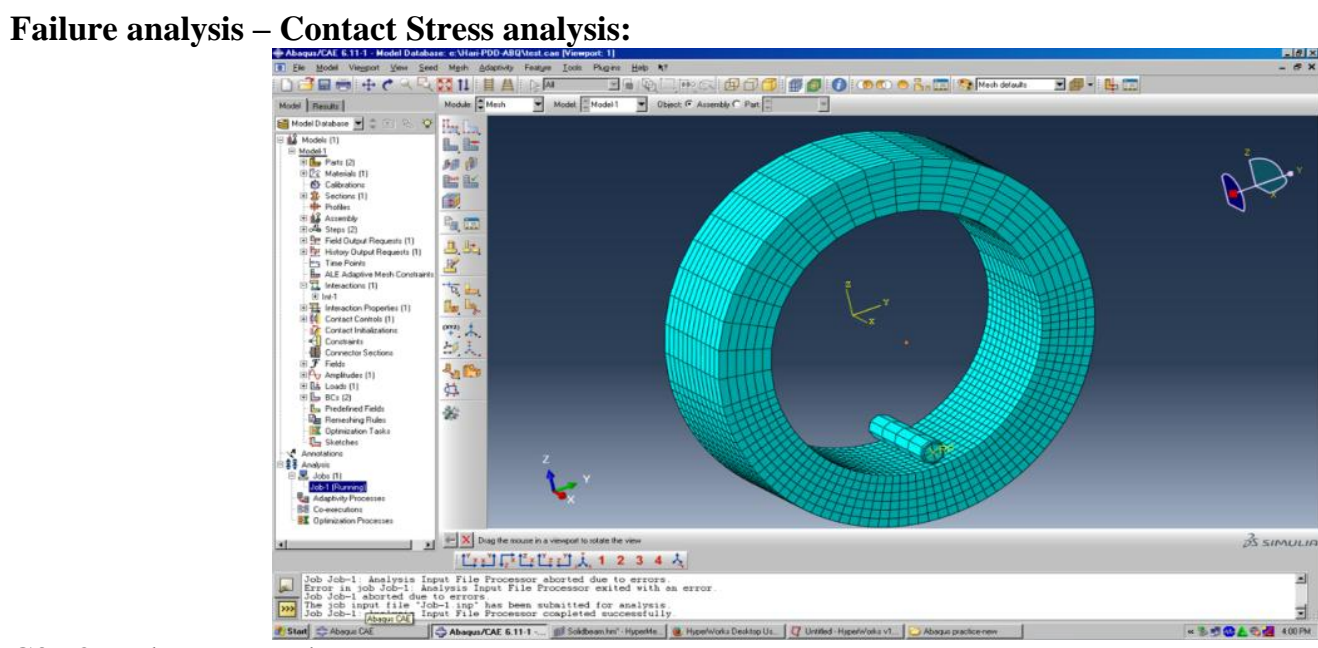

C3D8R element used

\section{Contact angle for exiting \& proposed profile:}

Current design: - In Auto CAD, Roller, Needle \& Tripod diameter is drawing at 1:1 and Contact created with bottom most needle and checked for Gap in bottom side needles $\left(180^{\circ}\right)$. Only 3 needles was in contact \& contact angle is only $24^{\circ}$.

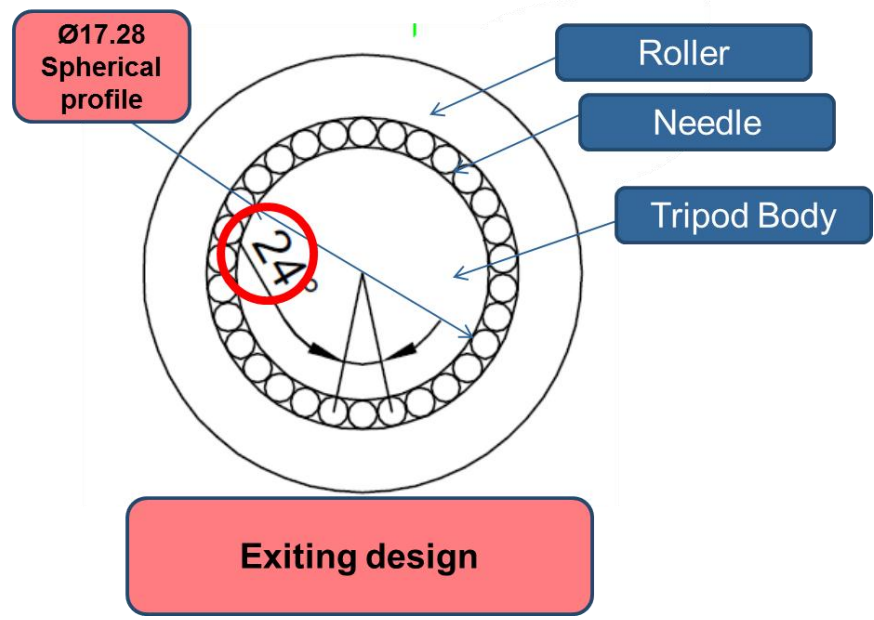

Figure 7 -Contact angle in same scale

Proposed design: -In Auto CAD, Roller, Needle \& Tripod diameter is drawing at 1:1 with Ovailty of $0.08 \mathrm{~mm}$ and Contact created with bottom most needle and checked for Gap in bottom side needles $\left(180^{\circ}\right)$. Observed 7 needles were in contact and contact angle is $72^{\circ}$

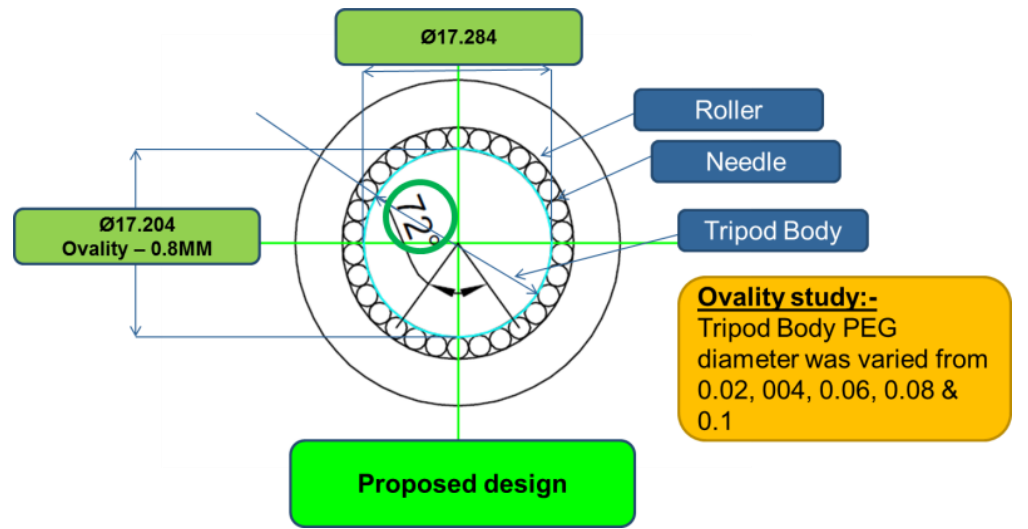

Figure 8-Contact angle by increasing the ovality in same scale 


\section{DESIGN OPTIMIZATION}

Three design iterations were made by modifying the Tripod PEG diameterin various combinations and by ensuring static load of all design iteration is greater than that of existing design as shown in Fig.9.

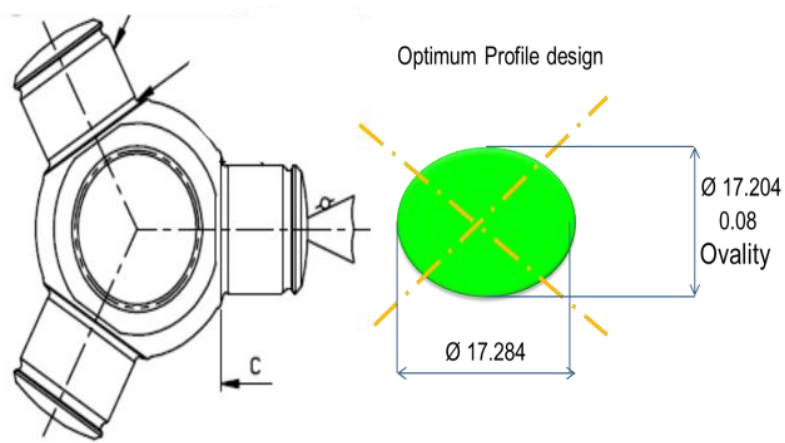

Figure 9-Oval profile of tripod Body in same scale

\section{Design Iteration 1}

In first iteration with the ovality of $0.02 \mathrm{~mm}$ existing $0 \mathrm{~mm}$ and simulated in Adams for static load distribution on tripod assembly is shown in Fig.10. The average and maximum Load distributions are 18.54 KN and $24.64 \mathrm{KN}$ respectively.
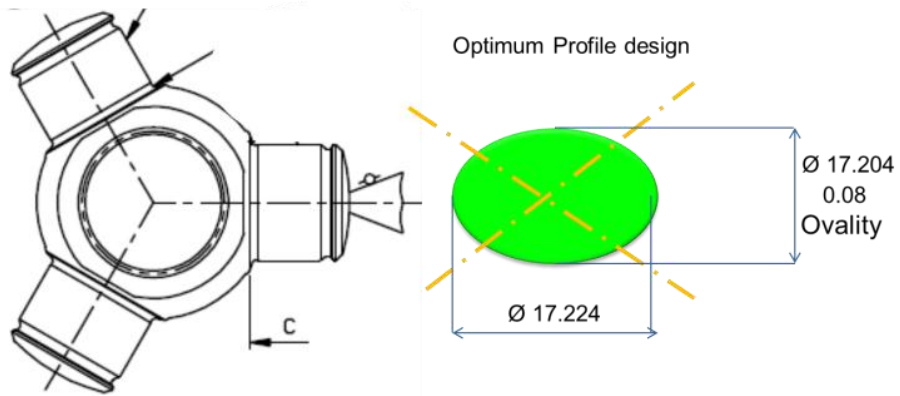

Figure 10-Tripod PEG ovality for iteration-1

\section{Design Iteration 2}

In second iteration with the ovality of $0.04 \mathrm{~mm}$ existing $0 \mathrm{~mm}$ and simulated in Adams for static load distribution on tripod assembly is shown in Fig.10. The average and maximum Load distributions are $16.45 \mathrm{KN}$ and $22.60 \mathrm{KN}$ respectively.

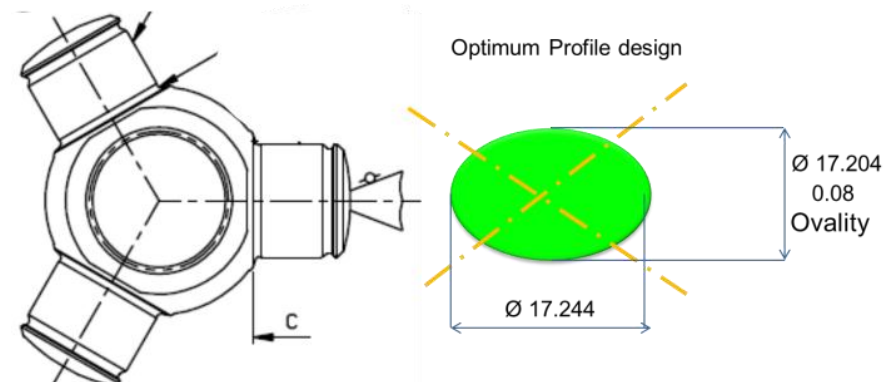

Figure 11-Tripod PEG ovalityfor iteration-2

\section{Design Iteration 3}

In third iteration with the ovality of $0.06 \mathrm{~mm}$ existing $0 \mathrm{~mm}$ and simulated in Adams for static load distribution on tripod assembly is shown in Fig.10. The average and maximum Load distributions are $15.75 \mathrm{KN}$ and $20.56 \mathrm{KN}$ respectively. 


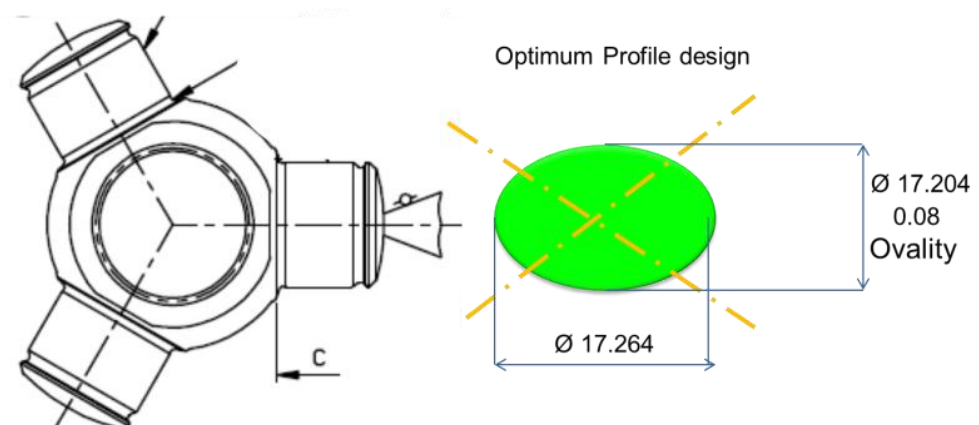

Figure 12-Tripod PEG ovalityfor iteration-3

\section{CONCLUSION}

The average and maximum load distribution on tripod Assembly for the maximum static load pressure of $1500 \mathrm{Nm}$ is greater than $1658 \mathrm{bar}$ and $1798 \mathrm{Nm}$ all three design iterations because of improving the ovality, this means all the three designs will work for maximum load distribution even though the load is high, anyhow design iteration-3 tripod body modeled with $0.08 \mathrm{~mm}$ showing lesserload than other iterations, also modifying the existing tripod assembly for iteration-3 is simple, so it is concluded to go with design iteration-3. The proto sample of the same is made by increasing the ovalityfrom omm to $0.08 \mathrm{~mm}$ and tested in same experimental setup.

Thus for high static load is meet in tripod assembly with ovality design tripods by optimizing the same using ADAMS / ANSYS,ADAMS results and experimental results were comparable and ADAMStechnique is effectively used to optimize the Ovality and load distribution. This analysis reduced the development cycle time and made to understand the load distribution.

\section{Acknowledgements}

I express my gratitude to Dr. Srinivasan, Professor and Director, AU-FRG Institute for CAD/CAM, College of Engineering Guindy, Anna University for allowing me to do the project and continuous encouragement for doing this project work. I also wish to express my deep sense of gratitude to Mr. GC.Streenath, Head of the Department, Manufacturing Engineering, GKN Driveline INDIA Ltd., Oragadam, for giving me an opportunity to do the project in the industry research environment.

\section{REFERENCES}

Tyler G Hicks (2006), "Handbook of Engineering Calculations", McGraw-Hill.

GKN Intranet - Design and standards Guide Lines

GKN - After markets websites

Constant-velocity joint - Wikipedia, the free encyclopedia websites

Rzeppa, Alfred H. (1927). Universal Joint. US patent no. 1,665,280.

NTN - Product review web site

US patent 1979768 , Pearce, John W.B., "Double Universal Joint", issued 1934-11-06

[8] US patent 2947158, King, Kenneth K., "Universal Joint Centering Device", issued 1960-08-02, assigned to General Motors Corporation

[9] Autodesk CFD simulation 2012 user's manual 